Value Based Approach for Recreational Planning in Horton Plains and Kawdulla National Parks in Sri Lanka

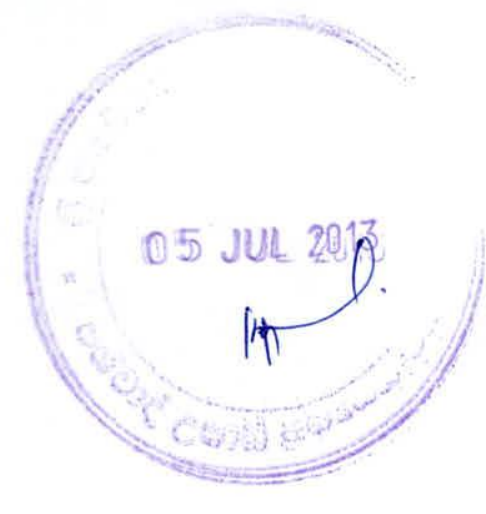

By

Rathnayake Mudiyanselage Wasantha Rathnayake (M.Sc, PG. Diploma, B.Sc. Sp. (Hons))

Thesis submitted to the University of Sri Jayewardenepura, Sri Lanka for the award of the Degree of Doctor of Philosophy in Environmental Economics. 


\section{DECLARATION}

I hereby certify that the work described in this thesis was carried out by me under the supervision of Dr. (Mrs.) U. A. D. P. Gunewardena, Senior Lecturer, Department of Forestry and Environmental Sciences of University of Sri Jayewardenepura, Sri Lanka, and a report on this has not been submitted in whole or in part to any university or any other institution for another Degree.

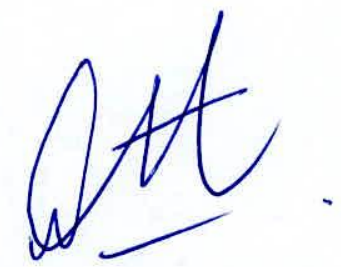

$4^{\text {th }}$ July 2013

R. M. W. Rathnayake 


\section{SUPERVISOR'S CERTIFICATION}

I certify that the statement made by the candidate is true and this thesis is suitable for submission to the Faculty of Graduate Studies of University of Sri Jayewardenepura for the purpose of the award of the degree of Doctor of Philosophy in Environmental Economics.

$4^{\text {th }}$ July 2013

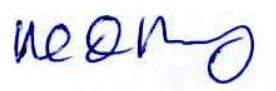

Dr. (Mrs.) U. A. D. P. Gunawardena Senior Lecturer

Department of Forestry and Environmental Sciences University of Sri Jayewardenepura Sri Lanka 


\section{Declaration by the Supervisor}

I certify that the candidate has incorporated all the corrections, amendments and additions recommended by the examiners.

vespresenthy

Supervisor

Dr. (Mrs.) U.A.D.P. Gunawardena

Senior Lecturer

Department of Forestry \& Environmental Sciences

University of Sri Jayewardenapura

Nugegoda

Sri Lanka 
2.6.2 Travel cost method 27

2.7 Recreational valuation of protected areas 30

2.8 Economic valuation techniques for protected areas 30

2.8.1 Market based methods 31

2.8.1.1 Market prices 31

2.8.1.2 Effect on production $\quad 32$

2.8.1.3 Replacement costs 33

2.8.1.4 Damage costs avoided 34

2.8.1.5 Mitigative or avertive expenditures 34

2.8.2 Non market based methods 35

2.8.2.1 Contingent valuation methods (CVM) 35

2.8.2.2 Surrogate market methods 35

2.8.2.3 Hedonic price method 35

2.9 Empirical economic studies and policy implications 36

2.9.1 Travel cost and contingent valuation studies 36

2.9.2 Contingent valuation combined travel cost studies $\quad 40$

2.9.3 Limitations of TCM 45

2.10 Ecotourism potential 46

2.10.1 Ecotourism and protected areas $\quad 46$

2.10.2 Empirical studies on ecotourism 49

2.10.3 Catalogues for assessing the ecotourism potential 52

2.11 Visitor satisfaction, characteristics and perceptions 53

2.11.1 Importance of studies on visitor satisfaction, characteristics and perceptions 53

2.11.2 Empirical studies on visitor satisfaction, characteristics and perceptions $\quad 54$

$\begin{array}{ll}2.12 & \text { Visitor carrying capacity }\end{array}$

2.12.1 Visitor induced impacts and park management 61

2.12.2 Empirical studies on VCC 61

$\begin{array}{llr}2.13 & \text { Conclusion } & 68\end{array}$ 


\section{METHODOLOGY}

3.1 Study sites $\quad 69$

3.1.1 Horton Plains National Park 69

$\begin{array}{llr}3.1 .1 .1 & \text { Location } & 69\end{array}$

$\begin{array}{lll}3.1 .1 .2 & \text { Climate } & 70\end{array}$

$\begin{array}{lll}3.1 .1 .3 & \text { Attractive viewpoints in HPNP } & 70\end{array}$

3.1.1.4 Importance and uniqueness of HPNP 73

$\begin{array}{lll}\text { 3.1.1.5 Existing visitor facilities at HPNP } & 74\end{array}$

$\begin{array}{ll}\text { 3.1.2 Kawdulla National Park } & 74\end{array}$

$\begin{array}{lll}3.1 .2 .1 & \text { Location } & 74\end{array}$

3.1.2.2 Climate 76

3.1.2.3 Attractive viewpoints at KNP $\quad 76$

3.1.2.4 Importance and uniqueness of KNP $\quad 76$

3.1.2.5 Existing visitor facilities at KNP $\quad 76$

$\begin{array}{ll}\text { 3.1.3 Visitation to HPNP and KNP } & 77\end{array}$

3.2 Conceptual framework for the study 80

3.3 Sample size and sampling plan $\quad 84$

3.4 Theoretical aspects and identification of quality of existing visitor 85 experience at HPNP and KNP

3.5 Identification of areas to be improved in the recreational planning 86

3.6 Information collection for recreational planning 86

3.6.1 Identification of ecotourism potential 87

3.6.2 Identification of visitor characteristics and perceptions $\quad 89$

3.6.3 Theoretical aspects and estimation of VCC 90

3.6.3.1 Questionnaire and scenario development 93

3.6.3.2 Data collection and questionnaire survey 95

3.6.4 Theoretical aspects of TCM and estimation of existing CS 95

$\begin{array}{ll}\text { 3.6.4.1 Questionnaire design } & 99\end{array}$ 
3.6.4.2 Data collection and questionnaire survey 100

3.6.4.3 Total travel cost (TTC) estimation 101

3.6.4.4 The econometric model applied in the study 102

3.6.4.5 Obtaining the statistical regression 103

3.6.4.6 Construction of the demand curve 103

3.6.5 Theoretical aspects of hypothetical travel cost method, scenario building 104 and estimation of $\mathrm{CS}$

3.6.5.1 Econometric model for HTCM 107

3.6.5.2 Questionnaire survey and data collection 108

3.7 The effect of imposing an entrance fee (distributional impact) 109

3.8 Present value of non market benefits from preserving the site 110

3.9 Implementation of recreational scenarios 111

$\begin{array}{lll}3.10 & \text { Conclusion } & 111\end{array}$

\section{CHAPTER FOUR}

RESULTS AND DISCUSSION

4.1 Descriptive statistics of the sample 112

4.1.1 Studies on visitor satisfaction and visitor characteristics and perceptions 112

4.1.2 Study on estimation of existing local CS at HPNP and KNP 114

4.1.3 Studies on estimation of CS at HPNP and KNP under the different scenarios 117

4.2 Quality of visitor experience and areas to be improved at HPNP and 117 KNP

4.2.1 Quality of visitor experience 117

4.2.2 Areas to be improved in recreational planning at HPNP and KNP 119

4.3 Ecotourism potential and resource inventories for HPNP and KNP 122

4.3.1 Ecotourism resource inventories for HPNP and KNP 122

4.3.1.1 Ecotourism resource inventory for HPNP 122

4.3.1.2 Ecotourism resource inventory for KNP $\quad 124$

4.3.2 Ecotourism potential at HPNP and KNP 126 


\subsection{Visitor characteristics and perceptions at HPNP and KNP}

4.4.1 Characteristics and perceptions of local visitors

4.4.2 Characteristics and perceptions of foreign visitors

4.4.3 Reasons for visiting HPNP and KNP

4.4.4 Willingness to pay for visitor facilities/services at HPNP and KNP

4.4.5 Rating of visitor attractions at HPNP and KNP

4.4.6 Suggestions to improve visitor satisfaction at HPNP and KNP

4.4.7 Some findings to be considered in recreational planning

4.4.8 Potential of ecotourism concession development for HPNP and KNP

4.4.9 Limitations and issues found in the studies on visitor survey

\subsection{Visitor carrying capacity}

4.5.1 Visitor carrying capacity at HPNP 157

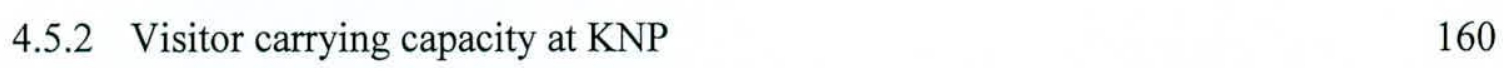

4.5.3 Relationship between crowding acceptance and socio-economic factors 161

4.5.4 Visitor carrying capacity and infrastructure 166

4.5.5 Limitations and issues found in the study of VCC 167

4.6 Estimation of existing consumer surplus of HPNP and KNP 170

4.6.1 Travel cost, opportunity cost and total travel cost at HPNP and KNP $\quad 170$

4.6.2 Estimation of visitation rates to HPNP and KNP 171

4.6.3 Demand functions for HPNP and KNP 174

4.6.4 Impact of increasing park entrance fee on park revenue 182

4.6.5 Estimation of optimum park entry fee 183

4.7 Measuring the quality of visitor experience in terms of consumer 186 surplus at HPNP and KNP

$\begin{array}{lll}\text { 4.7.1 Scenario building } & 186\end{array}$

$\begin{array}{lll}\text { 4.7.1.1 Scenarios for HPNP } & 187\end{array}$

$\begin{array}{lll}\text { 4.7.1.2 Scenarios for KNP } & 189\end{array}$

$\begin{array}{ll}\text { 4.7.2 Estimation of CS values under hypothetical scenarios } & 191\end{array}$

4.7.3 Resources required for implementation of alternative scenarios 199 
4.7.4 Impact of imposing an entry fee for study sites under alternative scenarios 201

4.7.5 Present value of non-market benefits from preserving the sites 207

4.7.6 Issues and limitations faced in the TCM studies 210

$\begin{array}{lll}\text { 4.7.6.1 Some practical issues } & 210\end{array}$

$\begin{array}{lll}\text { 4.7.6.2 Functional forms } & 210\end{array}$

4.7.6.3 Aggregation issues 211

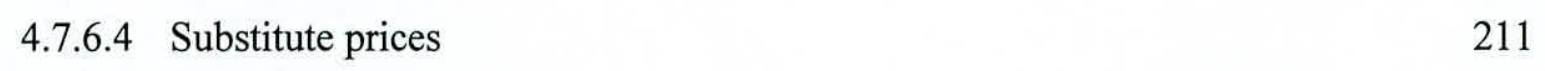

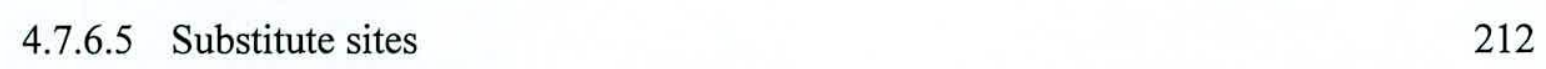

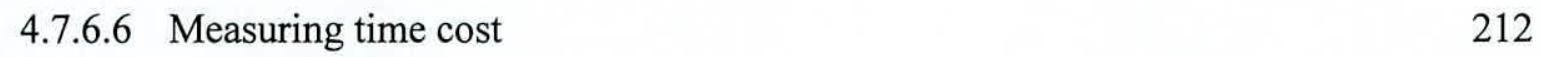

$\begin{array}{lll}\text { 4.7.6.7 Student visitors } & 213\end{array}$

$\begin{array}{lll}\text { 4.7.6.8 Multiple site visits } & 214\end{array}$

$\begin{array}{lll}\text { 4.7.6.9 Non-user values } & 214\end{array}$

$\begin{array}{lll}4.8 & \text { Visitor impact monitoring plan } & 217\end{array}$

$\begin{array}{lll}4.9 \text { Conclusion } & 219\end{array}$

$\begin{array}{ll}\text { CHAPTER FIVE } & 220\end{array}$

CONCLUSIONS AND POLICY IMPLICATIONS

$\begin{array}{ll}\text { REFERENCES } & 227\end{array}$

$\begin{array}{ll}\text { APPENDICES } & 273\end{array}$ 


\section{LIST OF TABLES}

Table 1.1 : Significant differences between HPNP and KNP 8

Table 2.1 : Wildlife protected area categories found in Sri Lanka 20

$\begin{array}{lll}\text { Table } 3.1 & \text { : Visitor statistics of HPNP } & 78\end{array}$

Table 3.2 : Visitor statistics of KNP 78

Table 3.3 : Framework for identification of ecotourism potential 88

Table 3.4 : Number of visitors for a particular scenario at HPNP 93

Table 3.5 : Number of vehicles for a particular scenario at KNP $\quad 94$

Table 3.6 : Numerical values for acceptable level with crowding at 94 viewpoints of HPNP

Table 4.1a :Local visitors' profile recorded in the study on visitor satisfaction

Table 4.1b : Local visitors' profile recorded in the study on visitor characteristics and perceptions

Table 4.1c : Foreign visitors' profile recorded in the study on visitor characteristics and perceptions

Table 4.1d : Local visitors' profile recorded in the study on visitor carrying capacity at HPNP and KNP

Table 4.1e : Mean zonal values of age, education, and household income recorded at HPNP and KNP

Table 4.1f : Respondents' profile in the hypothetical travel cost study

Table 4.2 : Weighted averages for visitor satisfaction at HPNP

Table 4.3 : Weighted averages for visitor satisfaction at KNP

Table 4.4 :Areas to be improved for enhancing the quality of visitor experience

Table 4.5 : Summary of ecotourism potential assessment at HPNP and KNP

Table 4.6 : Rating for ecotourism potential assessment at HPNP and KNP 
Table 4.7 :Signed ranks for pair of the study stites

Table 4.8 : Summary of characteristics and perceptions of local visitors

Table 4.9 : Summary of characteristics and perceptions of foreign visitors

Table 4.10 : Potential opportunities for community involvement in concession development at HPNP and KNP

Table 4.11 : Acceptability levels of crowding at each viewpoint at HPNP

Table 4.12 : Crowding standards for viewpoints at HPNP

Table 4.13 : Acceptability levels with a range of vehicles within $25 \mathrm{~m}$ radius at Kawdulla tank bed

Table 4.14a : Multinomial logistic function for crowding acceptability levels at Red Bridge

Table 4.14b : Multinomial logistic function for crowding acceptability levels at Chimney pool

Table 4.14c : Multinomial logistic function for crowding acceptability levels at Baker's fall

Table 4.14d : Multinomial logistic function for crowding acceptability levels at Mini World's end

Table 4.14e : Multinomial logistic function for crowding acceptability levels at World's end

Table 4.14f : Multinomial logistic function for crowding acceptability levels at KNP

Table 4.15 : Time costs, travel costs and total travel costs at HPNP and KNP

Table 4.16 : Zonal per 1000 population visitation rate (VR) and appropriate TTC at HPNP and KNP

Table 4.17 : Demand functions for visitation rates at HPNP and KNP

Table 4.18 : Calculation of the area under the demand curve for HPNP

Table 4.19 : Calculation of the area under the demand curve for KNP

Table 4.20 : Estimated results for demand functions for zonal travel cost study (park entrance fee vs number of visitors) 
Table 4.21 : Proposed recreational opportunities/schemes for HPNP under scenarios 1 and 2

Table 4.22 : Proposed recreational opportunities/schemes for KNP under scenario 1 and 2

Table 4.23 : Estimated results for regression analysis under hypothetical travel 192 cost study

Table 4.24 : Mean number of visits made by visitors at HPNP and KNP under proposed scenarios

Table 4.25 : Individual CS values with varying management scenarios

Table 4.26 : Required amount of expenditure and human resources for each scenario at HPNP and KNP

Table 4.27 : The changes in the number of visits and consumer surplus values under the proposed different park entrance fees at HPNP and KNP

Table 4.28 : Present value of benefits at HPNP and KNP 208

Table 4.29 : Proposed mitigation measures for minimizing environmental impacts due to recreational activities in national parks 


\section{LIST OF FIGURES}

Figure 2.1 : Distribution of protected area network in Sri Lanka 21

Figure 2.2 : Methods of environmental valuation 33

Figure 3.1 : Base map of HPNP $\quad 71$

$\begin{array}{ll}\text { Figure } 3.2 & \text { : Location map of viewpoints at HPNP }\end{array}$

$\begin{array}{lll}\text { Figure } 3.3 \text { : Base map of KNP } & 75\end{array}$

Figure 3.4 : Total number of visitors to HPNP and KNP from 2003 to $2010 \quad 80$

Figure 3.5 : Conceptual framework of the study 81

Figure 3.6 : Hypothetical social norm curve $\quad 92$

Figure 3.7 : Demand curve for travel cost method 104

Figure 3.8 : Consumer's surplus changes for hypothetical trips 106

Figure 4.1 : Mean weighted averages of variables used in identification of $\quad 120$ quality of visitor experience at HPNP

Figure 4.2 : Mean weighted averages of variables used in identification of quality of visitor experience at KNP

Figure 4.3 : Reasons for visiting HPNP

Figure 4.4 : Reasons for visiting KNP

Figure 4.5 : Willingness to pay for some visitor services/facilities at HPNP

Figure 4.6 : Willingness to pay for some visitor services/facilities at KNP

Figure 4.7 : Rating for improvement of some visitor attractions at HPNP

Figure 4.8 : Rating for improvement of some visitor attractions at KNP

Figure 4.9 : Suggestions of visitors to improve visitor satisfaction at HPNP 
Figure 4.12 : Social norm curve drawn for KNP tank bed

Figure 4.13 : Visitation rate (VR) vs total travel cost (TTC) for HPNP

Figure 4.14 : Visitation rate (VR) vs total travel cost (TTC) for KNP

Figure 4.15 :Demand curve for wildlife viewing at HPNP

Figure 4.16 : Demand curve for wildlife viewing at KNP

Figure 4.17 : Park entrance fee vs park revenue at HPNP and KNP

Figure 4.18 : Number of visits vs TTC at HPNP

Figure 4.19 : Number of visits vs TTC at KNP

Figure 4.20a : Number of visits vs TTC at HPNP (by distance) under scenario 1

Figure 4.20b : Number of visits vs TTC at HPNP (by distance) under scenario 2

Figure 4.21a : Number of visits vs TTC at KNP (by distance) under scenario 1

Figure 4.21b : Number of visits vs ttc at KNP (by distance) under scenario 2

Figure 4.22 : Fees and number of visits under alternative recreational scenarios at HPNP and KNP

Figure 4.23 : Number of visits vs consumer surplus values at HPNP and KNP under alternative scenarios

Figure 4.24 : CS values vs park entrance fee at HPNP and KNP under alternative scenarios

Figure 4.25 : Present values of benefits vs existing situation and alternative recreational scenarios 


\section{LIST OF APPENDICES}

Appendix 1 : List of Publications and Communications from thesis

Appendix 2 :The sampling plan for different questionnaire surveys

Appendix 3a :Questionnaire for visitor satisfaction survey at HPNP

Appendix $3 \mathrm{~b}$ :Questionnaire for visitor satisfaction survey at KNP

Appendix 4 :Checklist for resource inventory preparation for HPNP and KNP

Appendix 5a :Questionnaire for identification of visitor characteristics and perceptions at HPNP

Appendix $5 b \quad$ :Questionnaire for identification of visitor characteristics and perceptions at KNP

Appendix 6a-e :Questionnaires for visitor carrying capacity survey at HPNP

Appendix 6f :Questionnaire for vehicle carrying capacity at KNP

Appendix 7a :Questionnaire for zonal travel cost study at HPNP

Appendix 7b :Questionnaire for zonal travel cost study at KNP

Appendix 8a :Questionnaire for hypothetical travel cost study at HPNP

Appendix 8b :Questionnaire for hypothetical travel cost study at KNP

Appendix 9a :Resources inventory for HPNP

Appendix 9b :Resources inventory for KNP

Appendix 10 :Tables of data analysis under different studies conducted at HPNP and KNP

Appendix 11a :Visitor numbers for each increasing entrance fee calculated by using formulae no. (30) for HPNP

Appendix 11b :Visitor numbers for each increasing entrance fee calculated 


\begin{abstract}
by using formulae no. (31) for KNP
Appendix 12 :Results of paired t-test for null hypothesis testing under different scenarios

Appendix 13a : Estimated fund and human resources allocation for implementing proposed scenarios at HPNP

Appendix 13b : Estimated fund and human resources allocation for 378 implementing proposed scenarios at KNP
\end{abstract}

Appendix 14 : Developed impact monitoring formats 


\section{ACKNOWLEDGEMENTS}

I wish to express my deepest gratitude and sincere thanks to my supervisor, Dr. (Mrs.) U. A. D. P. Gunewardena, a Senior Lecturer, Department of Forestry and Environmental Sciences, University of Sri Jayewardenepura, Sri Lanka for her guidance, encouragement and valuable advice throughout the study and the preparation of this dissertation.

My sincere thanks to Prof. Hiran Amarasekera, the former Head, and Prof. Nilanthi Bandara, the present Head of the Department of Forestry and Environmental Sciences, University of Sri Jayewardenepura for granting permission for my study.

My special thanks go to Prof. Ranjith Bandara and Prof. Udith Jayasinghe Mudalige for their valuable comments and guidance for improving this dissertation. Further, my sincere thanks and kind appreciation are also due to my colleagues Mr. Ranjan Attygalle and Mr. K.S. Sivayesunnesan and Ms. H. D. Rajapakshe for providing me numerous supports to complete the study.

I would like to thank all of my colleagues for their assistance throughout the study.

Finally, my appreciation is extended to my loving parents and wife Mrs. S. D. R. S. Wijesinghe for their constant assistance and encouragement. 


\begin{tabular}{|c|c|c|}
\hline & & ABBREVIATIONS \\
\hline AMP & - & Accelerated Mahaweli Development Programme \\
\hline ASLP & - & Abijata Shala Lake National Park \\
\hline CBD & - & Convetion on Biodiversity \\
\hline CBSL & - & Central Bank of Sri Lanka \\
\hline CNPPA & - & Commission on National Parks and Protected Areas \\
\hline $\mathrm{CS}$ & - & Consumer's Surplus \\
\hline CVM & - & Contingent Valuation Method \\
\hline DWC & - & Department of Wildlife Conservation \\
\hline EEZ & - & Exclusive Economic Zone \\
\hline $\mathrm{EV}$ & - & Equivalent Variation \\
\hline FD & - & Forest Conservation Department \\
\hline FFPO & - & Fauna and Flora Protection Ordinance \\
\hline FSMP & - & Forestry Sector Master Plan \\
\hline GDP & - & Gross Domestic Production \\
\hline GWA & - & Grand Weighted Average \\
\hline HPNP & - & Horton Plains National Park \\
\hline HTCM & - & Hypothetical Travel Cost Method \\
\hline ITCM & - & Individual Travel Cost Method \\
\hline IUCN & - & World Conservation Union \\
\hline $\mathrm{JC}$ & - & Jungle Corridor \\
\hline KBNP & - & Kibale National Park \\
\hline
\end{tabular}




\begin{tabular}{|c|c|c|}
\hline KNP & - & Kawdulla National Park \\
\hline KuNP & - & Kuscenneti National Park \\
\hline MAB & - & Man and the Biosphere \\
\hline MENR & - & Ministry of Environment and Natural Resources \\
\hline MER & - & Managed Elephant Reserve \\
\hline MFE & - & Ministry of Forestry and Environment \\
\hline MFE & - & Ministry of Forestry and Environment \\
\hline $\mathrm{MnNP}$ & - & Minneriya National Park \\
\hline MNP & - & Marine National Park \\
\hline MWA & - & Mean Weighted Average \\
\hline NP & - & National Park \\
\hline NR & - & Nature Reserve \\
\hline NWTC & - & National Wildlife Training Centre \\
\hline OLS & - & Ordinary Least Squares \\
\hline $\mathrm{RP}$ & - & Revealed Preference \\
\hline RUM & - & Random Utility Model \\
\hline $\mathrm{SCC}$ & - & Social Carrying Capacity \\
\hline SLTB & - & Sri Lanka Tourist Board \\
\hline SLTDA & - & Sri Lanka Tourism Development Authority \\
\hline SNR & - & Strict nature Reserve \\
\hline SP & - & Stated Preference \\
\hline TCM & - & Travel Cost Method \\
\hline
\end{tabular}




$\begin{array}{ccl}\text { TTC } & - & \text { Total Travel Cost } \\ \text { UNEP } & - & \text { United Nations' Environmental Programme } \\ \text { UNESCO } & - & \text { United Nations Educational, Scientic and Cultural } \\ & & \text { Organization } \\ \text { UWNP } & - & \text { Uda Walawe National Park } \\ \text { VCC } & - & \text { Visitor Carrying Capacity } \\ \text { VERP } & - & \text { Visitor Experience and Resource Protection } \\ \text { VR } & - & \text { Visitation Rate } \\ \text { WCPA } & - & \text { World Commission on Protected Areas } \\ \text { WHC } & - & \text { World Heritage Convention } \\ \text { WLS } & - & \text { Weighted Least Squares } \\ \text { WTO } & - & \text { World Tourism Organization } \\ \text { WTP } & - & \text { Willingness to Pay } \\ \text { YNP } & - & \text { Yala National Park } \\ \text { ZTC } & - & \text { Zonal Travel Cost Method }\end{array}$




\title{
Value Based Approach for Recreational Planning in Horton Plains and Kawdulla National Parks in Sri Lanka
}

\section{Rathnayake Mudiyanselage Wasantha Rathnayake}

\begin{abstract}
Protection of the resources and provision of high quality visitor experience are the ultimate goals in recreational planning. Concern over rising visitation in parks, and accompanying impacts on resources and on visitor experience, and lack of adequate funds have been the major issues in the management of National Parks in Sri Lanka,
\end{abstract}

Although there have been certain quantitative and qualitative indicators for identifying the quality of visitor experience, economic values are rarely been used in recreational planning. The overall objective of the present study is therefore to propose a value based framework for recreational planning at Horton Plains National Park (HPNP) and Kawdulla National Park (KNP) in Sri Lanka in order to enhance the quality of visitor experience.

This study adopted the hypothetical travel cost method (HTCM) in order to examine how consumer's surplus (CS) changes could be applied in measuring the quality of visitor experience under different scenarios. Onsite surveys were conducted with 200 local visitors and 100 foreign visitors at each site in order to gather information on visitor characteristics and perceptions. Visitor carrying capacity (VCC) was estimated using a normative approach 
at five view points for HPNP and at one site for KNP using randomly selected visitors and acceptable levels were recorded and social norm curves were drawn for each viewpoint.

A zonal travel cost method (ZTCM) was applied with 200 local visitors at each site to estimate the present consumer surpluses. Ecotourism potential for both parks were assessed applying evaluation criteria for the available secondary data. The values obtained for each component was used in formulating recreational scenarios which presents improved recreational planning setup. Under each scenario, visitors are asked how many visits they would like to make to the site.

Results indicate that the ecotourism potential is high at both sites, and more ecotourism schemes and concessions could be developed for local community. Visitor characteristics are almost same at both sites and different views and perceptions were presented for improving ecotourism and visitor services at both parks. Results of the VCC study indicate that minimum acceptable number of vehicles within $25 \mathrm{~m}$ radius at KNP was nine. The VCC standards for viewpoints at red bridge, chimney pool, Baker's fall, mini and greater world's ends at HPNP are 21, 15, 38, 42 and 44 respectively. According to results of ZTCM, CS values per visitor (per visit) were Rs. 228.71 and Rs.370.16 at HPNP and KNP respectively.

Results of the HTCM indicate that visitors were willing to visit more than once within a year under improved condition. Therefore, under the scenario 1 at HPNP the CS per visitor was 
Rs. 3793.75, and it was Rs.7045.45 for scenario 2. For scenario 1 at KNP the CS per person was Rs.5433.33 and Rs.11295.00 was recorded for scenario 2 .

The present value of benefits (PVB) at HPNP and KNP based on the current CS values are Rs. 516.8 million and Rs. 19.2 million at 10 per cent discount rate. If the alternative scenarios are implemented the PVB for HPNP will be Rs. 6433.42 million and Rs. 15245.39 million for scenarios 1 and 2 respectively, at KNP these values will be Rs. 476.19 million and Rs. 1529.65 million under scenario 1 and 2 respectively. The estimated CS values are considerably higher than the current annual investment and operation expenditures of the HPNP and KNP. It could be concluded that if the value based approach is applied, the recreational planning could be done understanding the quality of visitor experience under alternative planning schemes.

Application of value based approach, diversification and establishment of new ecotourism and visitor services schemes, implementation of visitor impact monitoring programme, allocating more funds and human resources to conserve the undervalued natural resources, and introducing new fee structure for national parks are the major policy directions in the present study for both recreational planning and conservation of the natural resource base in national parks. 